\title{
A Qualitative Study of Stress in University Staff
}

\author{
George Mark \\ Centre for Occupational \& Health Psychology, \\ School of Psychology, Cardiff University, \\ 63 Park Place, Cardiff, CF10 3AS \\ Andrew P. Smith \\ Centre for Occupational \& Health Psychology, \\ School of Psychology, Cardiff University, \\ 63 Park Place, Cardiff, CF10 3AS
}

\begin{abstract}
Research has shown that university staff report high levels of stress. Most of this research has used questionnaires and the aim of the present study was to develop the area using interview data. The mixed responses given about the definition of stress reflect the definitional debates in psychology as whether "stress" is the cause of problems, or if it is the response. All of the participants claimed to either to have, or were currently experiencing stress, which illustrates how widespread stress at work can be. The wide range of stressors described shows the complexity and number of stressful situations that employees in academic employment can be faced with. Many of the consequences of stress at work described by participants related to anxiety and other symptoms of worry. Trouble sleeping was a common problem, as were issues relating to taking work worries home. There were various suggestions made about how to help avert or deal with stress in the workplace, and most of these centred around communication and better training and selection of management. Several participants believed that the university should be treated more like a business, with professional managers advised by professors. Nearly all of the participants were unsatisfied with the current method of selecting management on the basis of academic merit. The use and results of the interview methods illustrate that while questionnaire methods are typically more general and are thus applicable to a wider range of different populations, qualitative studies can give an extra dimension to results, and can provide key information about stressors and outcomes that questionnaires based on traditional stress models cannot. Indeed using interviews to guide the use of questionnaire selection, which could then be analysed in line with the structure of the DemandsResources-Individual Effects (DRIVE) framework, could be an important direction in future research on specific populations.
\end{abstract}

Keywords: university staff; stress; interviews; demands; resources; coping; individual differences; DRIVE model

\section{STRESS IN UNIVERSITY STAFF}

Research suggests that stress levels in universities are high (Abouserie, 1996; Fisher, 1994; Gillespie et al, 2001; Kinman, 2001, 2008; Kinman and Court, 210; Singh and Bush, 1998; Tytherleigh et al., 2005; Winefield and Jarrett, 2001). Mark and Smith (2012) investigated this issue using the Demands-Resources-Individual effects (DRIVE) model (Mark, 2006; Mark and Smith, 2008; Mark and Smith, 2012; Smith et al., 2009). Workplace demands, high intrinsic and extrinsic effort, negative coping and attributional style were associated with high levels of depression and anxiety in university staff. Williams et al. (2017) extended this research by including positive outcomes. Their results showed that negative outcomes (stress; anxiety and 
depression) were associated with job demands and negative coping. Positive outcomes (happiness; job satisfaction) were predicted by positive personality (high self-esteem, optimism and self-efficacy) and positive coping.

The majority of the research carried out on stress in university staff has been quantitative and in the present study qualitative methods were used to try and understand more about university employees' perceptions of stress and what they feel the term actually means. The research outlined in this paper was part of a larger multi-method study into stress and job characteristics, which combined multiple theoretical perspectives into a single approach. Job characteristics models (Karasek, 1979; Siegrist, 1996), transactional stress (Folkman and Lazarus, 1980), ways of coping (Vitiliano et al., 1985) and aspects of personality (e.g. attributional style, Sweeney et al., 1986) were investigated through a series of studies in order to develop a new model of stress (The DRIVE model). The work outlined here represents the qualitative element of this research. Qualitative methods were used to try and uncover more about some of the relationships between stressful work conditions and health that have not been captured in previous research. The method was also used to try and uncover more about some of the relationships between stressful work conditions and health that was not captured by the previous studies.

\section{Sample}

\section{METHODS}

As part of a questionnaire package in a study carried out on university employees (Mark and Smith, 2012) there was an optional section asking participants if they would be willing to take part in future research. Those who were interested, were asked to fill out a form with their name and contact details. After the questionnaires were collected, the pages with participants' personal details were removed. Contact details were selected at random for twenty individuals, and an email was sent to each which requested their participation in a short interview on work related stress, as a follow-up to the previous questionnaire study. Of the twenty individuals contacted, nine responded (45\% response rate) indicating they would be willing to participate, and these were seven women and two men ( $M=49.8$ years). Of those interviewed, six were university lecturers, and three were researchers. No administrative staff, IT staff, or professors were interviewed. Interviews were either conducted the participant's place of work, or at the office of the interviewer (at the preference of the interviewee).

\section{The Interview}

A semi-structured interview method was used, which was based on ten main points of interest, with further questions on these ten main topics being asked ad-lib to further the discussion as appropriate. At the start of the interview, the following statement was read aloud to all participants: "I am interested in the experiences and views of university employees about the topic of work stress. Your name won't be recorded. Participation is confidential and voluntary, and you can refuse to answer any questions if you don't feel comfortable. You can also withdraw from the interview at any time. Is it alright if I record the conversation for analysis?" After the interview, participants were informed that they could ask any questions about the study, or could contact the interviewer at a later date if they had any future enquiries, and that their data would be kept anonymously and destroyed after analysis.

There were multiple areas of interest for the interviews and these included: A focus on what the participants felt work stress actually was and if they had experienced it; What the causes of stress were for the participants, and the consequences to the individual and the group; How participants tried to deal with stress or its consequences, and their opinions on why some people can cope with stress and others can't; Finally they were asked who they felt was 
responsible for dealing with stress at work and what could be done about it. To analyse the data, the recorded conversations were listened to, and all relevant responses or any other interesting or key comments given, were noted for each participant on a spreadsheet. This enabled comparisons of responses for each participant across each question, as well as easy reference for any other significant statements or opinions. The ten specific questions asked are shown below, as well as descriptions of the general and interesting responses given across the sample.

\section{RESULTS}

The ten primary questions are shown below. "Cues" were also used if participants had difficulty in answering the questions, or were shy about responding.

\section{1) First I would like to ask you, what you think the term "work stress" actually means.}

The responses to this question varied among the participants with some describing the causes of stress, and others the symptoms. Several participants cited an inability to cope with problems or work tasks as a sign or symptom of stress, as well as negative emotions manifested through excess crying or fear of going to work. Several participants described stress as problems caused by work conditions, or when work negatively affects feelings. Other issues mentioned that relate to stress included job insecurity, overwork or high workload, feeling uncomfortable with work situations and circumstances, taking work worries home, sleep problems, exclusion from cliques, family conflict, and low control.

\section{2) Have you ever experienced work stress yourself? Cue: Have you seen other people stressed?}

In response to this question, all nine participants said that they had either in the past or were currently experiencing stress at work, and of these, two claimed to be experiencing stress constantly. One participant claimed to have experienced it in the past, but not currently. Eight participants claimed to have seen evidence of stress in co-workers, and one participant said "Everybody is stressed, but it's how people differ in responding to it that matters".

\section{3) What do you think it was that made you stressed? Cues: A specific incident, or general day to day hassles. Any other examples?}

Three participants gave examples of specific causes or incidents that had given rise to significant stress and ill health for them. For one participant, the source of stress was a difficult boss, who constantly shouted and "terrorised" her employees, and who according to the participant was constantly arrogant and short with colleagues. This caused friction, fear, and a bad atmosphere at work, and led to the participant being afraid to go into work, to have constant crying spells and poor performance. In the end the participant claimed that she felt she had no course other than to leave her job at the end of her contract. Another participant's major source of stress was the slow and inefficient procedure for the renewal of a short term work contract. The contract was due to end the week after participation in the interview, and no decision had yet been made as to whether the contract would be renewed. The participant claimed that this had caused her to worry about money and mortgage repayments, and had caused frustration, constant anxiety and crying, sleep problems, and problems with her partner. She was further incensed that her stress should have been totally avoidable, and was due to the slow and inefficient nature of the renewal process, that in her view showed no respect for employees. Finally, the third participant claimed that the cause of her stress occurred when two university departments were merged, and she had been demoted to a job that she had held twelve years previously. She also no longer had her own office, and was doing the same job as people she had previously been in charge of. She claimed that the stress 
associated with this incident had caused two to three years of physical and mental health problems, and she "had never really recovered".

In addition to these three specific incidents, there were a large number of everyday problems and hassles that many participants cited as contributing to stress, over time the build-up of which had serious consequences for some participants. Examples of stressful circumstances and conditions were many and varied, and one participant alone cited all of the following as stressors they had experienced in the past: bad management and unprofessional or inept bosses and line managers; selfish co-workers who didn't take account of others; short term contracts and lack of security; long hours; bullying at work and aggressive, violent, or threatening colleagues; the pressure to publish papers, carrying out teaching, finding funding, and juggling these different roles; work-family conflict; a lack of job control; and unhelpful workplace mentors. Many of the above stressors were cited repeatedly by other participants, particularly issues to do with lack of communication with colleagues. Other common stressors mentioned by participants included exclusion from the decision making process, constantly changing assessment procedures with no guidance, unfair distribution of work, excessive paperwork and bureaucracy, "changing goalposts", lack of support, and moaning or complaining colleagues.

Several participants noted that workload stress did not come from absolute level of workload, as they stated that high workloads were to be expected, but that unexpected or last minute increases in workload, that disrupted previous plans or goals were very stressful. Indeed these events were described by two participants as particularly stressful when they were imposed by superiors who had known about the work in advance, but had not informed the employee. However, there was one kind of stressor that eclipsed all others, both in frequency of being mentioned, and in intensity of consequences, and this stressor was to do with poor management. Seven of the nine participants claimed that they had in the past or were currently suffering stress due to managers who had poor management skills. These criticisms included managers who allegedly knew less about their job or department than their employees, who were aggressive, violent, or abusive, who deliberately avoided dealing with stress-related issues, who gave no social support, who openly had favourites among their subordinates, or who took no notice of employee needs. The majority of participants agreed that these problems were directly related to the fact that university managers are not trained managers, i.e. they are very often academics who are good at managing research, but are often unsuited to the task of managing individuals. Two participants had come from medical or nursing backgrounds, and claimed that the level of stress in university employment was significantly lower than had been in their previous jobs. One of these participants claimed that despite suffering from some stress, her job was "a party" in comparison to the stress levels she had suffered from as a nurse, and claimed that her co-workers "didn't know what stress really was".

\section{4) What were the consequences to you of work stress? Cues: Any effects on physical health, mental health, or home life?}

The consequences for participants of workplace stressors were as varied as the types of stressors themselves. Stress related outcomes for participants included physical and mental problems, problems with work-life balance, and absence behaviours. The most common consequence given by participants were problems or difficulty with sleeping, either from inability to sleep, restlessness from worry, or staying up late to work. Other examples given included: Being afraid of going into work; arguments with partners; money worries; excessive drinking; several participants described increased incidence of illness, particularly flu and colds; irritability and a shortening of temper; inability to stop thinking about work; feeling 
burnt out; crying; feelings of frustration and being alone; resentfulness; hyperactivity; excessive tiredness; poor performance and increased incidence of making mistakes at work; an inability to relax; and depression.

\section{5) How do you normally try and deal with stress at work? Cues: Problem focused coping, speaking to people, ignoring it, not taking work home?}

The most commonly cited way of trying to deal with stress related problems was related to seeking social support and talking about the problem. Seven of the participants gave "talking to colleagues" as their primary way of dealing with problems at work. Usually the content of this was related to seeking support or advice on how to fix problems, or for confirmation that a problem issue had occurred. Participants appeared to favour talking to colleagues as a first step, and talking to managers afterwards. However, one participant stated that she never talked about work problems to colleagues as they "moaned constantly" and were no help, so she instead sought support from her family. Several other participants also stated that they regularly sought support from family as well as colleagues. Two participants did not mention seeking support at all, and favoured self-reliant problem-focused approaches, such as putting things into perspective, avoiding aggression, or getting on with things and working overtime. Other examples of dealing with stress included the setting of personal deadlines, keeping informed, prioritising workload and planning, and making lists. One participant cited the use of alternative therapies as important to her in dealing with work stress, and another participant said that he and his colleagues had set up regular working lunches and coffee breaks to discuss workplace problems and seek solutions, and claimed that this was a very effective method of dealing with problems before they escalated.

\section{6) Why do you think some people can deal with stress and others can't so well? Cues: Age, gender, or personality differences?}

All of the participants thought that there were individual differences in ability to deal or cope with stressful situations at work. Around half of the participants believed that older or more experienced individuals were better equipped to cope with stress, because they were more confident or had "seen it all before". Four participants believed that men were less likely to get stressed than women, and either were more laid back, more in control, or let it just "go over their heads", but one participant claimed that men were more aggressive and more likely to be "Type A" and thus create their own stress. Other participants said that there are differences in ways of coping that affect stress, such as being better at time management or having good planning skills. One participant said that some people are "natural worriers" who are likely to internalise stress and make matters worse for themselves.

\section{7) Who do you think is responsible for dealing with stress? Cues: Employees themselves, management, the university, departments, supervisors?}

Most participants said that there was a broad spread of responsibility for dealing with stress, with several being adamant that it was a line manager's responsibility to detect stress in employees and support them. However most claimed that it was the individual who was most responsible for confronting their own stress (or "taking ownership" of it as one participant stated) and to go about seeking ways to relieve it. Two participants claimed that it was the university's responsibility to provide more information about stress, so that people could avoid being stigmatised, and would be less likely to worry about being labelled. Several other participants said that the primary responsibility lay with schools or departments to provide resources to help. 


\section{8) What do you think could be done to help deal with stress? Both generally, and in your} work situation.

There were various suggestions made about how to help avert or deal with stress in the workplace, and most of these centred around communication and better training and selection of management. Several participants believed that the university should be treated more like a business, with professional managers advised by professors. Nearly all of the participants were unsatisfied with the current method of selecting management on the basis of academic merit. One participant stated that there should be more opportunity for feedback to discuss problems, and that the exclusion of employees from the decision making process was "a joke", and if there was such a system in place, that it was not publicised. One participant had asked for help from the university, and was told to speak to her manager, when in fact the cause of her stress was related to conflict with her manager. Another participant said that she believed that there was a counselling service in place for employees, but she didn't know how to use it or where to go, and she would have definitely used such a service had she known of it when she had been suffering from severe work stress. Most participants said they had no idea if there were any counselling or support systems in place for stress-related problems.

Several participants stated that communication was the key issue, and there had to be more face to face communication, and less electronic or paper communication, as well as people to talk to for help who were independent of management and university bureaucracy. Others stated that there was too much paperwork, when workloads were already high, and that more efficient practices or a smaller amount of paperwork was needed, or else that others should be employed to do paperwork so that university staff could "get on with the jobs they were supposed to be doing". That the university and professors didn't care about employee welfare was a common feeling, with much resentment directed at line managers and departmental heads. Several participants suggested that University departments needed to work harder to foster an inclusive culture where stress wasn't stigmatised, and to give more information about how to detect stress, and where you could go for help.

\section{9) Do you think your job is more or less stressful than the average in the UK? Cues: What kind of jobs do you think are the most stressful?}

Despite all of the participants claiming that they had suffered from work-related stress in academia, seven of the participants stated that their job was generally average in terms of stress, and with the exclusion of very specific stressful events (such particular frictions with a boss, or a lack of contract renewal) with none stating that it was more stressful than average. Only two participants stated that their job was less stressful than average, with both of these coming from healthcare backgrounds. One of these participants stated that anything to do with public service was far more stressful than academia, and gave the examples of police work, the fire service, and nursing.

\section{0) What do you think are the effects on the university of stressed out staff? Cues: Affects students, home life?}

Several participants stated that stress at work caused morale problems in the workplace, with colleagues being "dragged down", and about half of the participants agreed that students may suffer as a result due to worse teaching and absent staff. One participant said that she only went to her GP for help with stress after her students expressed their concern for her deteriorating health. Others stated that stress caused problems with team working, as well as resentment from other staff who receive extra work as a result of the stress-related absence of a colleague. 


\section{DISCUSSION}

The responses given to the above questions provide important information about many aspects of stress and stressors that could not have been gained from the questionnaires used, or from any other quantitative methods. For example, the mixed responses given as to what participants thought the definition of stress was, are interesting as they reflect the definitional debates in psychology as whether "stress" is the cause of problems, or if it is the response. Also the range of views expressed highlight that there is no fixed definition of stress, particularly in the public domain. However most individuals seemed to describe stress as related to their emotional or affective feeling or response, rather than the presence of psychosocial stressors per se. The fact that all of the participants claimed to either to have, or were currently experiencing stress, illustrates how widespread stress at work can be, even in a sample not traditionally seen as stressed like university employees. Indeed, two participants stated that despite suffering from stress, this was a normal thing that everyone had to deal with, and one participant stated that a little bit of stress was good for motivation. This suggests that university employees and perhaps many people in other working domains, may accept moderate stress as a normal feature of working life.

It is also important to note, that in some cases a single event or poor relationship gave rise to high levels of stress and negative outcomes (which lasted for many months in two participants) when for these participants, all other aspects of their jobs were not stressful. Indeed, traditional measures of psychosocial stressors (such as levels of workload, control, or reward) may not detect conflict with a boss, or job security fears. This illustrates the need to be aware that there may be stressors present for individuals that traditional quantitative measures may not detect. This also provides support for the use of a single "how stressful do you find you job" measure, as a good way of initially detecting conditions or issues that may put individuals at risk of stress-related problems. Indeed such a method could be useful for both indicating where more investigation is needed, as well as setting in motion the processes to head-off potential stress problems, rather than just detecting its presence by measuring the levels of absence, negative health, or other stress-related outcomes.

The wide range of stressors described shows the complexity and number of stressful situations that employees can be faced with which is particularly striking given that all of the current participants work in a similar area of academic employment. Despite the broad range of stressors given, which included stressful interactions with colleagues, bullying, having to juggle multiple roles, etc, it was surprising that the most commonly cited stressors were not the "traditional" stressors of job demands or workload, but were far more related to communication and social interaction at work. Most participants accepted that high workloads were just part of being an academic, and thus were not really regarded as a particular stressor. However, unexpected workloads, changing deadlines, or extra work were mentioned as being particularly stressful by several participants. This suggests that as long as workloads are predictable, then they did not often pose a particular problem for the participants, but that work or workloads that are "sprung upon" participants could cause issues. While some participants were frustrated at being excluded from the decision making process, which is related to a lack of control, this was often framed in terms of a communication issue. Indeed, no participants cited a lack of control over their own work as a problem, but rather a lack over control over the larger work environment, to do with policy and how things were run. Poor communication, particularly with managers in the form of being "kept out of the loop" seemed to be a key issue for most of the participants.

Many of the consequences of stress at work described by participants related to anxiety and other symptoms of worry. Trouble sleeping was a common problem, as were issues relating to 
taking work worries home, which is related to overcommitment or intrinsic effort from the ERI model. Only two participant stated that they had suffered depression as a result of stress, with all participants citing anxiety as a problem (however it is possible that chronic anxiety could lead to depression outcomes for some) and frustration and annoyance at work problems were also common. However, consequences for job satisfaction were rarely mentioned by participants, and an enquiry about how stress affects satisfaction should in hindsight, possibly have been mentioned as a cue. It is interesting that while the most common stressor mentioned by participants was a lack of communication and conscientiousness from colleagues and managers, the most common method of trying to deal with stress was by seeking social support and advice from colleagues. In other words, the most common stressor and the most common coping mechanism were in the same domain. This echoes the predictions made by the Demand-Induced-Stain-Compensation model (de Jonge et al. 2000) which proposed that each kind of demand would be "compensated" by resources in the same domain, for example, social demands by social resources, emotional demands by emotional resources, cognitive demands, by cognitive resources, etc.

Most participants believed that getting other perspectives and sympathy regarding work problems was the most effective means of dealing with problems, particularly if talking to coworkers could provide a solution. This is interesting, given the lack of "seeking advice" as a strong predictor of health outcomes in the qualitative research. Either seeking advice as operationalised in the coping questionnaire was not an accurate representation of advice seeking in the interview sample, or advice seeking as a positive coping mechanism may be confounded with advice seeking as a behavioural response to stress, that is not related to positive coping. While other more problem-focused coping methods such as prioritising, making plans and maintaining self-reliance were mentioned, they were not seemingly as popular as communication-type approaches. The method of setting up regular communications by using working lunches and coffee breaks to talk about problems, as suggested by one participant, sounds like an appealing and inclusive coping method, because if a lack of communication is a stressor in itself, such methods could not only be useful for dealing with existing stressors, but could also pre-empt potential problems. Regarding individual differences between ability to cope with stress, participants all agreed that these differences did exist, but most did not specify how or why, other than suggestions that men cope better, or that more experience leads to better coping ability. Participants had more divided opinions on who was responsible for dealing with stress at work. With some maintaining that individuals were responsible on their own, and others that managers should be better at detecting stress. However nearly all participants agreed that the university needed to do more to highlight the problems of stress for employees, and that more should be done to make employees aware of where they could go for help and what services were available. This is related to what many participants believed could be done to help deal with stress, with most agreeing that more needed to be done, particularly with dissemination of information about stress, better and more transparent communication, and better training and selection of managers and those in charge of departments. The observation that all participants had experienced stress, but that all either claimed their job was average or less than average in stress, again raises the interesting point that many people think that stress is a normal part of everyday work today.

\section{How did the interviews relate to our previous survey?}

While the interviews conducted were only on a small percentage of the participants used in the questionnaire study, they provide important information about the experiences and views of stress-related health in a university staff population. However, due to the relatively openended nature of interviews, and thus the specific and individual nature of the responses, these findings may be less directly applicable to other sample populations, but it is likely that other 
similar work environments (e.g. teachers, public sector workers, etc) may have similar experiences or views. The interview responses of participants showed that there were some important psychosocial stressors that were not specifically covered in the independent variables as used in the previous studies. For example the strong contribution of management style, communication, and employee inclusion in the decision making process to levels of stress in the workplace. It was also an interesting finding that it was not overall level of workload that seemed to contribute to stress for employees, but rather unpredicted workload, or where rules and policies governing workload or performance were changed without employee input. Also the contribution of management style and training, and bullying or aggression in managers and co-workers, to stress and negative health outcomes was not covered in the independent variables from the previous studies. Results showed that while the majority of independent variables (coping, job demands, control, social support, intrinsic effort) did appear to have contributions to make for individual experiences of stress, other variables used in the quantitative research were not mentioned as much, however this may in part be due to the lack of specific questioning about attributions, beliefs, rewards, job satisfaction, etc. While there is no doubt that the number of independent variables used in the quantitative research is greater than in the majority of similar work stress research, the results of the interviews shows that there are still many important potential stressors that were not included as independent variables, at least as for university employees. Perhaps some of the variance in the outcomes not accounted for by the included IVs may be attributable to such factors, and this possibility could be explored in future research. Indeed, it is likely that had the qualitative interviews been carried out in the initial stages of the research rather than the latter stages, the quantitative work reported in our earlier survey may have benefited by way of better selection of variables. The use and results of the interview methods here therefore, illustrate that while questionnaire methods are typically more general and are thus applicable to a wider range of different populations, qualitative studies can give an extra dimension to results, and can provide key information about stressors and outcomes that questionnaires based on traditional stress models cannot.

\section{Results in relation to DRIVE model}

As previously outlined, the work here supplements a body of quantitative research designed to create and test a new model of stress, job characteristics, and individual differences, through a range of questionnaire studies based on key theories from the literature. However, while the results of the interview study show that there are certain important points not covered in the questionnaire studies, this does not raise doubts about the structure of the empirically supported DRIVE model. This is because the use of broad general purpose variables, such as job demands, ways of coping, intrinsic rewards, etc, are still applicable to a wide variety of occupations (although some specific stressors from university populations may have not been included). However, the DRIVE model is proposed to be a general purpose framework, and relevant variables for specific populations can be inserted as applicable. For example in future research, university job role, management style, bullying etc, may be important independent variables that could be placed into the model. Indeed using interviews to guide the use of questionnaire selection, which could then be analysed in line with the structure of the DRIVE framework could be an important direction in future research on specific populations. Therefore the interview study described above gives some extra insights into stress and health outcomes in university lecturers and researchers, particularly the importance of management and communication in the workplace, and that interviews could be used in addition or previous to questionnaire studies, to target stressor-health outcomes in specific populations. The results also show how important it is to be aware that many factors can contribute to stress and ill-health at work, and that general purpose factors such as workload-related job demands, ways of coping, etc, may be applicable in a general sense to a wide variety of 
populations, but that specific independent variables can be as, or even more important in specific populations.

\section{References}

Abouserie, R. (1996). Stress, coping, strategies and job satisfaction in university academic staff. Educational Psychology, 16(1), 49-56. doi:10.1080/0144341960160104.

de Jonge, J., Bosma, H., Peter, R., \& Siegrist, J. (2000). Job strain, effort-reward imbalance and employee well-being: a large-scale cross-sectional study. Social Science and Medicine, 50, 1317-1327.

Fisher, S. (1994). Stress in Academic Life: The Mental Assembly Line. Buckingham, UK: Open University Press.

Folkman, S., \& Lazarus, R.S. (1980). An Analysis of coping in a Middle-Aged Community sample. Journal of Health and Social Behaviour 21, 219-239.

Gillespie, N. A., Walsh, M., Winefield, A.H., Dua, J., \& Stough, C. (2001). Occupational stress in universities: staff perceptions of the causes, consequences and moderators of stress. Work \& Stress, 15(1), 53-72. doi: 10.1080/02678370117944.

Karasek, R. (1979). Job demands, job decision latitude and mental strain: Implications for job redesign. Administrative Science Quarterly, 24, 285-306.

Kinman, G. (2001). Pressure points: review of research on stressors and strains in UK academics. Educational Psychology, 21, 473-492. doi: 10.1080/01443410120090849.

Kinman, G. (2008). Work stressors, health and sense of coherence in UK academic employees. Educational Psychology, 28(7), 823-835. doi: 10.1080/01443410802366298.

Kinman, G. and Court, S. (2010). Psychosocial hazards in UK universities: adopting a risk assessment approach. Higher Education Quarterly, 64(4), 413-428. doi: 10.1111/j.1468-2273.2009.00447.x.

Mark, G. (2006). Work Stress in University Staff. Occupational Health Psychology - Key Papers of the European Academy Vol 7.

Mark, G. M., \& Smith, A. P. (2008). Stress models: A review and suggested new direction. In: Occupational Health Psychology: European Perspectives on research, education and practice. Vol. 3. EA-OHP series. Edited by J.Houdmont \& S. Leka. Nottingham University Press. 111-144.

Mark, G., \& Smith, A. P. (2012a). Effects of occupational stress, job characteristics, coping, and attributional style on the mental health and job satisfaction of university employees. Anxiety, Stress \& Coping, 25(1), 63-78. doi: $10.1080 / 10615806.2010 .548088$.

Mark, G., \& Smith, A. (2012b). Occupational Stress, Job Characteristics, Coping and the Mental Health of Nurses. British Journal of Health Psychology, Sep;17(3):505-21.

Siegrist. J. (1996). Adverse health effects of high-effort/low-reward conditions. Journal of Occupational Health Psychology, 1, 27-41.

Singh, S. N. \& R. F. Bush (1998). Research burnout in tenured marketing professors: An empirical investigation, Journal of Marketing Education, 20(1), 4-15. doi: 10.1177/027347539802000102.

Smith, AP, Wadsworth, EJK, Chaplin, K, Allen, PH, \& Mark, G. (2009). The relationship between work/well-being and improved health and well-being. Leicester: IOSH.

Sweeney, P., Anderson, K., \& Bailey, S. (1986). Attributional Style in Depression: A Meta-Analytic Review. Journal of Personality and Social Psychology, 50, 974-991.

Tytherleigh, M.Y., Webb. C., Cooper, C.L. \& Ricketts, C. (2005). Occupational stress in UK Higher Education Institutions: a comparative study of all staff categories. Higher Education Research \& Development, 24(1), 41-61. doi: $10.1080 / 0729436052000318569$.

Vitaliano, P.P., Russo, J., Carr, J.E., Maiuro, R.D., \& Becker, J. (1985). The Ways of Coping Checklist Psychometric Properties. Multivariate Behavioral Research, 20, 3-26.

Williams, G., Thomas, K \& Smith, A.P. 2017. Stress and Well-being of University Staff: an Investigation using the Demands-Resources- Individual Effects (DRIVE) model and Well-being Process Questionnaire (WPQ). Psychology, 8, 1919-1940. https://doi.org/10.4236/psych.2017.812124

Winefield, A. H., \& Jarrett. R. (2001). Occupational Stress in University Staff. International Journal of Stress Management, 8(4), 285-298. doi: 10.1023/A:1017513615819. 